BRIEF REPORT

\title{
Epidemiology of electrical and lightning related deaths and injuries among Canadian children and youth
}

\author{
B H Nguyen, M MacKay, B Bailey, T P Klassen
}

Injury Prevention 2004;10:122-124. doi: 10.1136/ip.2003.004911

See end of article for authors' affiliations

.....................

Correspondence to:

Dr B H Nguyen, Hôpital

Ste-Justine, 3175 Chemin

Côte-Ste-Catherine,

Montréal, $\mathrm{PQ}$, Canada

H3T 1C5.

bich_h_nguyen@

yahoo.com

\begin{abstract}
Among burn injuries, electrical injuries constitute a small but devastating fraction. To describe the epidemiology of electrical injuries in Canadian children, data on deaths and emergency department visits related to electrical injuries, including lightning strikes, were obtained from provincial coroners' offices and the Canadian Hospitals Injury Reporting and Prevention Program (CHIRPP) respectively, for the years 1991-96. Twenty one deaths and 606 emergency visits highlight that electrical related deaths, more frequent among school age children, are more likely the result of high voltage and lightning strike, while emergency department visits, more frequent among younger children, are more likely the result of low voltage. While the introduction of legislated standards for child safe outlets and educational programs for parents, children, and youth are recommended strategies toward reducing the frequency of these incidents, these strategies require further evaluation before their effectiveness can be estimated.
\end{abstract}

B eyond the first few months of life, injuries become the most frequent cause of death and long term disability in children. ${ }^{1}$ Serious burns are one of the most life altering types of injury, often requiring years of painful rehabilitation. Among burn injuries, electrical injuries (including lightning strikes) constitute a small but devastating fraction. Mortality and morbidity resulting from electrical injury have not been previously reported for the paediatric population in Canada. The purpose of this study was to describe the epidemiology of electrical injuries in the Canadian paediatric population from 1991-96 using the two routinely collected data sets with the greatest amount of detail surrounding injury circumstance.

\section{METHODS}

Data on all fatalities from 1991-96 in children aged 0-19 years resulting from electrocution, including lightning strikes, were requested from the 10 provincial and two territorial coroners' offices across Canada. Data include age, sex, year of injury, source of electrical current, type of injury, and injury circumstances. An annual paediatric mortality rate for electrocution, including lightning strike, was calculated using age specific population data for the same period. Data on all emergency department visits for children 0-19 years related to electrical injury, including lightning strikes and for the years 1991-96 were requested from Health Canada's Canadian Hospitals Injury Reporting and Prevention Program (CHIRPP). ${ }^{2}$ While not population based, these data characterise injury related emergency department visits to 10 paediatric and five general hospitals in Canada. They provide a rich source of circumstantial information and have been shown to be reasonably representative, ${ }^{3-5}$ and are estimated to describe approximately $16 \%$ of injuries to Canadian children (personal communication, Margaret Herbert, Injury Section, Health Surveillance Canada, September 2002). Data include age, sex, year of injury, setting, injury circumstance, and disposition.

\section{RESULTS}

During the time period examined there were 21 deaths due to electrocution among children in Canada. Five of these (24\%) were the result of lightning strike. This number may underestimate the true number of electrical injury deaths, as data were available from all coroners' offices except Nova
Scotia where the information system is not currently automated. In addition, the data released for Ontario for 1995-96 were considered preliminary. Table 1 describes the deaths by source of electrical current and age of victim. The median age for high voltage electrical deaths was 13.2 years and for lightning strike 14.2 years. All but one of the fatalities was male and all but two occurred outdoors. Younger children (5-9 years) were more likely to be electrocuted while playing around electrical company installations (for example, trespassing around electrical substations), while older victims were more likely to be electrocuted or struck by lightning while working near or around their house (for example, pruning trees, fixing TV antennae). One high voltage incident in Quebec in 1991 killed three adolescents simultaneously when the TV antennae they were erecting under adult supervision touched a 25000 volts electrical line. An annual rate of electrical death (including lightning) for Canadian children 0-19 years was calculated at 0.045/ 100000.

A total of 606 electrical injuries, including nine cases of lightning strike, were reported to CHIRPP from 1991-96. None of these injuries resulted in a fatality and there was no overlap with the coroners' data during this period. Thirteen percent of CHIRPP cases required admission to hospital, 25\% were held for observation, and $42 \%$ required treatment and some degree of follow up. Sixty percent of those injured and $70 \%$ of those hospitalised were male. Table 2 describes injuries by circumstances and age of victim. While $68 \%$ of the electrical injuries occurred in $0-4$ year olds; this age group made up only $42 \%$ of hospitalised CHIRPP cases. Ten to 14 year olds, who made up 13\% of injuries, represented 34\% of hospitalised CHIRPP cases. Seventy seven percent of the injuries occurred in the victim's own home or yard and the most common circumstance was a child placing an object or finger in an electrical outlet or device $(42 \%)$.

\section{DISCUSSION}

The current study is limited in that the picture of paediatric electrical injury for Canada presented is incomplete. The mortality data available were incomplete and hospitalisation data were not presented due to the cost of obtaining them. While the CHIRPP data provide useful detail not available from other sources, it is likely that they under-represent that 
Table 1 Coroners' reported electrocution deaths by source of current and age, Canada, 1991-96

\begin{tabular}{llllll}
\hline & \multicolumn{4}{l}{ Age of victim (years) } & \\
\cline { 2 - 5 } Source of current & $\mathbf{0 - 4}$ & $\mathbf{5 - 9}$ & $\mathbf{1 0 - 1 4}$ & $\mathbf{1 5 - 1 9}$ & Total \\
\hline Lightning strike & 0 & 1 & 2 & 2 & 5 \\
Voltage $\geqslant 1000$ volts & 0 & 4 & 2 & 8 & 14 \\
Voltage $<1000$ volts & 1 & 1 & 0 & 0 & 2 \\
\hline
\end{tabular}

Table 2 CHIRPP reported electrical injuries by circumstance and age, 1991-96

\begin{tabular}{|c|c|c|c|c|c|}
\hline \multirow[b]{2}{*}{ Circumstance } & \multicolumn{4}{|c|}{ Age of victim (years) } & \multirow[b]{2}{*}{ Total (\%) } \\
\hline & $0-4$ & $5-9$ & $10-14$ & $15-19$ & \\
\hline Placed object/finger in outlet & 229 & 18 & 7 & 3 & $257(42)$ \\
\hline Appliance/electrical device & 115 & 41 & 42 & 19 & $217(36)$ \\
\hline Put cord in mouth & 35 & 2 & 0 & 0 & $37(6)$ \\
\hline Touched live wire* & 13 & 7 & 6 & 3 & $28(5)$ \\
\hline Water involved & 7 & 6 & 8 & 3 & $24(4)$ \\
\hline $\begin{array}{l}\text { Touched } 2 \text { sources of electricity } \\
\text { at once }\end{array}$ & 3 & 8 & 4 & 1 & $16(3)$ \\
\hline Struck by lightning & 1 & 2 & 5 & 1 & $9(1)$ \\
\hline Othert & 3 & 0 & 7 & 2 & $18(3)$ \\
\hline Total (\%) & $411(68)$ & $84(14)$ & 79 (13) & $32(5)$ & 606 \\
\hline
\end{tabular}

actual number of emergency department visits related to electrical injury. This may be particularly true for older adolescents who are more likely to be seen at adult emergency rooms. Despite being incomplete, however, the available picture does provide evidence that electrical injury including lightning strike is a real and preventable issue in the Canadian paediatric population.

That the annual death rate of $0.045 / 100000$ children 0-19 years for Canada was much lower than the rate in the United States of $0.73 / 100000$ for the same time period is notable. ${ }^{6}$ The exact reason for this discrepancy is unclear, but may be in part the result of an underestimate in Canadian deaths due to the incomplete data and differential exposure related to climactic differences. In this analysis electrical injury death appears to be a greater issue for school age children (5-19 years) than younger children. This is likely the result of increased exposure to lightning and high voltage $(\geqslant 1000$ volts) lines either because of activities being undertaken in the outdoor setting (for example, yard chores, sports, and recreational activities) or increased risk taking behaviour (for example, trespassing in high voltage installations). The Lightning Safety Group, a consensus panel in the United States, have developed guidelines that constitute a summary of safest practices based on the research and experience available in $1998 .^{7}$ Current best practice to prevent lightning injuries focuses on educational strategies. For high voltage efforts focus on regulation of power line installation, ${ }^{8}$ installation of underground electrical lines, ${ }^{9}$ and educational efforts-which may be best targeted at adolescents who appear to be at greater risk due to increased exposure.

While the greatest number of deaths occurred in older children, the majority of less severe injuries occurred in children 0-4 years. In our study, non-fatal electrical injuries in children appear to be typically the result of low voltage current originating from household electrical outlets. Fortunately, similar to previous studies, most of these injuries are minor requiring little or no treatment. ${ }^{10}$ However, the children in this age group did make up $42 \%$ of hospitalised CHIRPP cases. Unlike the United States where cord biting appears to be a greater issue, ${ }^{811}$ contact with low voltage electrical outlets, whether direct (for example, mouth or finger) or indirect (for example, fork or other implement), was the most frequent cause of injury in the current study. The reason for this discrepancy is unclear and it may be that multinational studies examining differences in circumstances and prevention strategies may guide best practice. Proposed strategies to address the prevalent hazard include legislated standards for the manufacture and use of child safe electrical outlets and the addition of electrical injury prevention to educational programs for parents and children. Research suggests that to be effectively "child safe" electrical outlets should be engineered to meet four criteria. They should be permanent fixtures on the wall; have an automatic shield closure to limit access (a more passive measure than requiring the use of socket plugs); consist of parts of a sufficient size not pose a choking risk; and include labels addressing age appropriateness. ${ }^{12}{ }^{13}$

There are several "child safe" outlet designs on the market, however their direct effectiveness has not been rigorously evaluated and without evidence of effective design it is too early to assess the effectiveness of an enforced standard requiring their installation. Educational programs addressing age specific hazards exist, but not all include hazards associated with electrical injury. ${ }^{14}$ Whether this is an oversight or the result of a prioritisation of hazards concomitant with injury risk, as with other areas of injury prevention it is likely that a multipronged approach including education to support environmental changes will prove most effective. Yet even if legislation of environmental changes with associated educational programs is the way to proceed, careful evaluation and enforcement of any legislation are necessary. Finally, although primary prevention is the ultimate goal, the education and training of health care professionals and first responders with respect to how to triage and treat victims of lightning strike and other electrical injuries is also important to limit the impact of electrical injuries. ${ }^{15}$

\section{Authors' affiliations}

B H Nguyen, B Bailey, Division of Emergency Medicine, Department of Pediatrics, Hôpital Ste-Justine, Université de Montréal, Montréal, Quebec 
M MacKay, Plan-it Safe, The Child and Youth Injury Prevention Centre, Children's Hospital of Eastern Ontario, Ottawa, Ontario T P Klassen, Department of Pediatrics, Stollery Children's Hospital, University of Alberta, Edmonton, Alberta

\section{REFERENCES}

1 Baker SP. The injury fact book. Lexington, MA: Lexington Books, 1984

2 Mackenzie S, Pless IB. CHIRPP: Canada's principal injury surveillance program. Inj Prev 1999;5:208-13.

3 Macarthur C, Pless IB. Evaluation of the quality of an injury surveillance system. Am J Epidemiol 1999;149:586-92.

4 Macarthur C, Pless IB. Sensitivity and representativeness of a childhood injury surveillance system. Inj Prev 1999;5:214-16.

5 Pickett W, Brison RJ, Mackenzie SG, et al. Youth injury data in the Canadian Hospitals Injury Reporting and Prevention Program: do they represent the Canadian experience? Inj Prev 1996;6:9-15.

6 National Center for Health Statistics. Vital statistics of the United States. Vol II, part A, statistic 1990-1992 and NHCS website's data warehouse at www.cdc.gov/nchs/ for data1993-1996 (search conducted in March 1999).
7 Lightning Safety Group. Lightning safety group recommendations. Phoenix, Arizona: American Meteorological Safety Conference, 1998.

8 Rabban JT, Blair JA, Rosen CL, et al. Mechanism of pediatric electrical injury: New implications for product safety and injury prevention. Arch Pediatr Adolesc Med 1997; 151:696-700.

9 Thompson JC, Ashwal S. Electrical injuries in children. Am J Dis Child 1983;137:231-5.

10 Garcia C, Smith G, Cohen D, et al. Electrical injuries in a pediatric emergency department. Ann Emerg Med 1995;26:604-8.

11 Baker MD, Chiavello C. Household electrical injuries in children. Am J Dis Child 1989;143:59-62.

12 Bond M. Strategies to prevent household electrical injuries in children. Am J Dis Child 1989;143:1130-1.

13 Ridenour MV. Age appropriateness and safety of electric outlet protectors for children. Percept Mot Skills 1997;84:387-92.

14 American Academy of Pediatrics. Office-based counseling for injury prevention. Pediatrics 1994;94:566-7.

15 European Resuscitation Council. Part 8: advanced challenges in resuscitation. Section 3: special challenges in ECC. 3G: electric shock and lightning strikes Resuscitation 2000;46:297-9.

\section{LACUNAE}

\section{A revolution: speed cameras cut speed}

t a time of high unemployment and religious tensions, one issue grips the French:

speed cameras. According to one poll, they are the top subject of conversation, put there by $82 \%$ of respondents. To the indignation of drivers who had so far escaped these devious devices and their fines, some 100 cameras were installed last autumn. A further 900 are coming in the next two years. For people used to speeding with impunity, the shocking thing is that they work.

Last year, for the first time in 30 years, the number of deaths on French roads fell below 6000 - a drop of $21 \%$ from 2002. Ministers have fallen over themselves to claim credit. Reducing road deaths was one of Jacques Chirac's election pledges. And with reason: every year, more than twice as many people die on the roads in France as in Britain.

But the efficiency with which these machines have deterred speed junkies has baffled the French. A critical survival skill in a rule bound society is to know how to break the rules. The country suffers from what Jean-Louis Debré, president of the National Assembly, calls "legislative inflation". The yearly statute books have grown in size from 1020 pages in 1989 to 1600 in 2002.

In general, the more rules, the more they are broken. No smoking in the office? No dog poo on the pavement? No double parking? Pouff! Such intrusions into personal liberty are met by a shrug of indifference. The French even have an expression-faire sauter les $P V$ (skipping fines)—for getting speeding fines waived by pulling political strings, a practice that automatic fines have stopped. "Violating legislation", writes Béatrice Houchard in Road Delinquency, a new book, "is a national sport".

Hence the perplexity over the speed cameras. "It's a small revolution", commented Le Monde, noting the "incredible fact" that the French seem to be driving more slowly, even on Paris's ring road. Rémy Heitz, a road safety minister, calls the change a "veritable psychological rupture". A case study in the transformation of a national psyche? Or a simple lesson that zero tolerance works? (contributed by Peter Jacobsen, from The Economist). 